\title{
Human Ecology — Between Idleness and Labour
}

\author{
Irina Kavinova \\ Bauman Moscow State Technical University \\ 5/1, 2nd Baumanskaya St. \\ Moscow, Russia 105005 \\ E-mail: irinapk. @ Bk.ru
}

\begin{abstract}
The article examines the problem of ecology of a human, studies the correlation between self-knowledge and "self-concern" in the ancient culture, explores the existential phenomena of idleness and labor in the historical context. It also distinguishes various forms of "fatigue" in relation to the life of a modern human: physical, psychological, creative and patrimonial. The author gives an ambiguous assessment of the existential of laziness.
\end{abstract}

Keywords—self-knowledge; "self-concern"; idleness; existential of laziness; work; "birth fatigue"; human ecology

\section{INTRODUCTION}

Today, the issue of a human preserving themselves is risen more and more often, and more and more rarely we perceive with irony the assertion that the "Red Book" with its last line should have a human being as a vanishing biological species. Up to what extent the modern human is concerned about their own destiny, how much the cares about themselves, what is historical context of this "care" - these are the benchmarks we would like to rely on in the study of the problem of the human ecology.

In the extraordinary culturological study of G. Ivanchenko, "Self-concern: history and modernity", one correlation is indicated, which caused our special interest. Considering the historical aspect of the problem under study, the author writes: "Taking care of yourself" is a rare example of how, having arisen, a whole vast field of concepts, discussions and practices plunged into the region of silence and oblivion - until very recently. The saying "Get to know yourself" was so famous, and little importance was given to the call to "take care of yourself" (epimeleia heautou), in European philosophy, in contrast to the philosophy of the East" [1].

Indeed, the ancient philosophical thought, choosing between the egocentrism of Socratic dialectics and the rationalism of Aristotelian approaches in cognition, preferred, as it seems to us, exactly "cognizing" instead of "taking care". In the future, the specificity of such a preference in ancient epistemology may have predetermined the development of classical scientific knowledge in the usual attributes for us: the subject, method, law, the logical and mathematical matters of formalizing the theory, etc. [2]. Even such a brilliant figure in the history of philosophy as Hegel, with his attempt to replace the logic of the correct forms of Aristotle with the dialectical logic of working with a contradiction, could not radically change anything in the current situation.

Later, in the twentieth century, due to a big amount of extraordinary discoveries in science, it was necessary to break the habitual stereotypes of the "Faustian culture": to experiment with the formalization processes in science, to invent new philosophical languages, to use metaphor on all possible and "impossible" levels of cognition (from "Oedipus complex" to " black holes"). However, all this humanitarian" omnivorousness" has not solved the problem of the peculiar rational narrowness of European science. This narrowmindedness of rational approaches in the anthropological sphere was manifested most vividly [3]. Hardly anyone today will dispute the thesis that postmodernism in the broadest interpretation of this term is essentially a fixation of the crisis of European rationality. The crisis in this case does not mean "death", on the contrary, it seems to us a certain point of "bifurcation", with which the movement to new landmarks in cognition begins. Our time is filled with eclectic combination of incongruous: science with religion and mythology, technical creativity with poetry, psychology with theater, and even medicine with music.

\section{ORIGINS OF THE ANTIQUE PREFERENCE OF LOGOS TO INTUITIVISM OF "DIALECTICOS"}

In this context, it is interesting to analyze the origins of the ancient preference for the rationality of the logos to the intuitionism of dialectic search ("dialecticos"), the preference for mathematized knowledge ("no geometer let it enter") of the peculiar "concern" of the secret of one's own existence: preferences, because intuitionism has always been present, as if it came on the heels of rational "self-knowledge", not disappearing, but only from time to time, being in its shadow (see Eric Robertson Dodds, "The Greeks and the Irrational" (1949) [4].

The starting point of the discrepancy between "selfknowledge" and "concern" can be the figure of the Athenian ironic and maieutic Socrates, which is not original at all, but, in our opinion, is fair. Socrates, who wrote nothing, is known to us primarily in the discourse of the two of his followers: the didactically driven historian Xenophon, and Plato, who brilliantly assimilated his dialectical method. So, Socrates is responsible for three interpretations of the essence of cognition. 
The first of the knowledge provisions attributed to Thales, and not to Socrates, sounds like an ironic appeal: "Know thyself", and we hear the Aesopian: "Drink the sea". Embossed in stone on the pediment of the Delphic church, this statement attracted Socrates as a kind of motivation for action, in this case, to self-knowledge as almost hopeless work.

The second of the provisions was a consequence of the first one, it was indicated in the process of a Socratic immersion into the depths of the cognition of the nature of a human by means of maieutics, i.e. the art of helping the truth birth in the form of co-conversation (dialecticos), and was expressed by Socrates in the resulting sophism: "I only know that I do not know anything."

Finally, the third interpretation of the possibilities of cognition turned out to be the proposition that only virtue is the true knowledge, and exactly the same statement about virtue and knowledge among the followers of Socrates, Xenophon and Plato, does not exist, but there are variations of the transposition of this thesis, the most famous of which is criticism of this position for excessive rationalism by Aristotle, who never met Socrates. In a more complex and subtle way than other interpreters of Socrates's thought, Plato often refers to good life as a virtue, knowledge is the art of measuring of a smaller and bigger good for oneself (see Plato's dialogue Meno) [5].

If the Sophists shocked everyone with an equation - truth means good for me - then Socrates posed a counter-problem: "So what is the good for me?". In Plato's rendering, we read about how Socrates discusses the paradox of human understanding of the good: often people ask the gods for welfare, after getting it, they realize the worthlessness and meaninglessness of the requested, but they do not give up hope for happiness (eudaemonia), the nature of which remains for them completely unclear.

Obviously, Socrates provoked not only his interlocutors but, according to his own words in the Apology of Plato, all his state of Athena to acquire an in-depth understanding of the care of their own well-being (attached to the city, like an importunate gadfly to a sleepy horse).

The ancient world, which existed in cyclic time, did not record the dates of birth and death of people but was sensitive to the achievements of people at the age of flourishing (acme) and to how a person - worthy or not worthy - left this land. Worthy of respect and even admiration, Socrates's departure from life (he was executed because of false accusations) finally solved the dispute about the nature of the good and the knowledge about it in his favor. The ancient world began to unravel Socratic fearlessness in front of the cup with the cicuta and his paradoxical understanding of eudemonia and good. It can be said that Socrates transferred his in-depth search for selfknowledge into the plane of genuine self-concern, concern about one's own life and one's own virtue.

In the history of philosophy, Socrates becomes a cult figure and is most often regarded as an ethical rationalist (Georg W. Friedrich Hegel, Søren A. Kierkegaard, Friedrich
W. Nietzsche, Neo-Kantians, etc.), and only artistic creativity (antique and modern - from Apuleius to E. Radzinsky), who build stories on contradictions and paradoxes, guessed more sensitively the ambiguity and peculiar irrationalism of Athenian ironic [6].

Once a problem of true understanding of the good for oneself arose on the path of an in-depth self-knowledge, one can undoubtedly assert that this search has turned into some sort of philosophical "concern". In fact, it is at the point of profound disclosure of the essence of eudemonia (as a good one by all parameters), that self-knowledge and "selfconcern" came together in life. Dynamic knowledge changed into care, self-concern encouraged the in-depth selfknowledge. It is at the intersection of knowledge and concern that we see the ancient world stating the problem of leisure, or high aristocratic idleness.

\section{LEISURE OR ARISTOCRATIC IDLENESS IN THE ANCIENT WORLD}

Leisure is perceived by ancient people of the classical epoch (that is, the golden age of ancient culture) as a manifestation of a high aristocracy that is not correlated with concrete work, as a "feast" of intellect, when wine is diluted with water to expand the chances of conversation. "Essentially, aristocratism transforms any action into an idle one, just as a petty bourgeois puts on everything in the form of labor," we read in the curious article "Idleness and Laziness" by Olga P. Zubets [7]. However, in the same ancient world, "sybaritism", idleness in the form of primitive nothingness, is despised and even subjected to physical destruction: it is enough to recall the history of Pythagoreans' war against Sybaris and its inhabitants.

Let us dwell on the story of Sybarites death, which is quite indicative for the ancient world. The city of Sybaris, called Croton, like the city where the refugee from Samos Pythagoras, settled, was located on the Italian lands. These lands had already been colonized by Hellenes in the 8th century BC. Sybaris prospered both economically and politically but the citizens of this policy knew no measure, i.e. violated the "golden rule" of one of the seven sages: "Measure first". For the Hellene of the archaic era, as, indeed, in later times, this is not just a rule - it is a lifestyle that manifests itself in everything from organizing feasts to building temples.

Sybarites knew no limits in clothes, cosmetics, sex, but especially in indulging their palate (the achievements of cooks were similar to the achievements of military leaders). The measure was broken definitively after Sybarites mercilessly attacked the peaceful Pythagorean negotiators who had come to the city to petition for refugees from Sybaris and asked for defense in Croton. An internecine war between the two policies broke out. Apparently, the knowledge of Pythagoras helped Crotons under his leadership not only to win the military victory over Sybarites, but also, using the geographic features of the natural landscape, to flood the city, so that the Sybaris ceased to exist in general, teaching a lesson to the future descendants. 
Later, the term "sybarite" was fixed in ancient culture to a pampered loafer, a "cake-eater", and received an exceptionally negative interpretation. Even Seneca in his writings noted a story about a sybarite that could not fall asleep on a bed of roses because one of the petals, having bent, rubbed his shoulder (almost the artistic prototype of the future fairy tale of Hans Ch. Andersen "The Princess and the Pea"). We can say that reasoning about the proportionality between self-knowledge and self-concern inevitably leads to thinking about the nature of the relation between idleness and work, work and laziness.

Having abandoned the household, Socrates, being not very interested in politics, day and night on every street corner was looking for a person to talk to about nothing as it seems: about beauty, wisdom, cowardice in itself, and etc. It means "pushing his interlocutor to general concepts" without any apparent purpose, from idle interest, to be convinced not only in the completeness of his own, but also in universal ignorance. Who is he - a loafer or aristocrat in the highest sense of the word? After Socrates was executed, his intellectual heritage gave birth to distinctive successors: the Socratic schools of Cyrenaica, Megaric and Cynic appeared, and Plato created the Academy. Plato's Academy existed for centuries. After its closure in the 6th century BC with the help of the Emperor Justinian, it, like a Phenix, revived consistently in three cities of medieval Italy of the fifteenth century. Reflected by the light of Plato's dialectics and pedagogy, the world of philosophy and culture continues to live to this day.

Megarics-eristics were carried away by the sophistical refinements of Socratic thought, Cyrenaics brought the search for eudemonia (happiness) to the absurd form of equating a successful life to "easy death", which in Roman times was called "euthanasia." And only the Cynics, who did not seem to behave like system philosophers, as they shocked the ancient world with their eccentric manners and contempt for politicization and comfort, turned out, as we see it, to be the true followers of Socrates' high concern for achieving a good life.

Cynic Diogenes was called, according to Plato, "the crazy Socrates". His disdain for external goods gave birth to many legends and even more interpretations: from serious to comical. However, as Diogenes Laertius tells us, the Athenians respected this metic from Sinop so much that they honored his posthumous monument, and he himself was called a "heavenly dog", in one name combining contempt with respect. "To the question as to what philosophy gave him, he replied: "In any case, be prepared for all the strokes of fate ", we read about the Diogenes cynic in Laertius's "Lives and Opinions of Eminent Philosophers". No one cared so little for themselves, like the students of Antisthenes from Cynosarges, but at the same time, no one led a more free (carefree) way of life from all obligations, while recognizing labor as the main good. "The sage does not live according to the laws of the state, but according to the laws of virtue," Antisthenes said [8].

Can the cynical contempt for all goods except for the good to remain oneself outside politics ("cosmopolitanism"), beyond comfort, be considered a genuine self-concern and a form of a lofty idleness, for it was the cynics who opposed themselves to the aristocratic ideal of calocagathy (worshiping everything exquisitely beautiful). In our opinion, in some cases - yes, in other cases - no. If the evaluation were unambiguous, then the cynicism would not have developed in Roman times into a different form of attitude to life and man - cynicism (obscenity).

\section{THE EXISTENTIAL NATURE OF LABOR AND LAZINESS}

So, our reasoning leads us to one more dilemma: labor and laziness, what is the nature of this phenomena of human nature. In order not to be lost in the various interpretations of the indicated relationship, let us focus only on what seems to be important in our own existential field of perception of the world. Work can be interesting, challenging, creative, etc. One can continue to list the epithets inherent in labor, for quite a long time, the only thing that makes labor practically impossible is its total meaninglessness ("Sisyphean labor"). In "Notes from Underground" F.M. Dostoevsky showed that even hard labor with a given goal - "lesson" - ceases being hard.

On the other hand, laziness has always been an elusive phenomenon of human existence. We can say that a lazy person is the most authentic, like Oblomov, "stuck" to his couch, but at the same time he was quite contented with himself and he was absolutely different from others. Perhaps the source of laziness is fatigue. But then what is the cause of this fatigue? And what is the real nature of fatigue?

If we consider the phenomenon of fatigue, starting from scratch, it turns out that there are several important gradations of this phenomenon in the existential field of a man: physical fatigue, psychological fatigue, creative fatigue, and finally the fatigue of the entire human race (generic fatigue) with loss of life's impulse, or "will to live."

The physical fatigue is relieved by various body relaxing procedures, the description of which is not the task of this study, and the simplest procedure is a well-known healthy good sleep. It is believed that physical fatigue is easier to get rid of than compared to psychological fatigue, but it should be noted, that the ultimate physical fatigue is a death for creativity, and therefore, for the self-realization of a personality, which was brilliantly demonstrated by Jack London in the novel "Martin Eden": exhausting labor does not leave room for anything else but sleep or its ugly deputy -an artificially invigorating "drug" in the form of drunkenness, rude entertainment and so on. The severe physical fatigue can act dangerously on the human psyche, leading us to the displacement of all moral regulators, even to crime: in this context, A.P. Chekhov's story "I Feel Like Sleeping," which describes an unreasoned story, is indicative.

The psychological fatigue, or some kind of a melancholic attitude to life, also poses a danger for the individual, preventing first of all building one's life with the full realization of one's own possibilities: constant being in pessimistic moods can encourage original creativity but rarely brings satisfaction to the melancholic, who is "bored" because of imperfection of everything and "tired of life". The 
examples of bored "Onegins" in the literature of the nineteenth and twentieth centuries are numerous, which is clearly an indicator of the prevailing mental state of the human civilization in the last two centuries [9]. A vivid example of the psychological fatigue is the life and fate of S. Kierkegaard, talented and at the same time "unhappy".

The creative fatigue is the most dangerous in manifesting self-aggression of the person: exhaustion of oneself, of one's talent is a cruel existential temptation to commit a suicide. The destinies of such creative personalities such as Jack London, Vladimir Mayakovsky, Sergey Yesenin, Marina Tsvetayeva and many other film directors and poets, singers and musicians who committed suicide or who deliberately brought themselves to the last point, were often associated with the creative fatigue, which seemed completely intolerable to these people. One can call it, referring to Jack London, the phenomenon of "deceiving the body" by a tired mind.

Finally, in our opinion, there is a general weakening of the will to live typical for modern mankind, which can be called the generic fatigue. In the European philosophical tradition, the consideration of this phenomenon is colored with all sorts of "colors": from Nietzsche's aphorisms to modern variants of postmodern art. In modern science, the weakening of the will to live is considered in the context of the destruction of the institution of the family, related to the phenomenon of "evolution on the contrary", i.e. the problem of saving a person from himself. The generic fatigue with special emphasis is also manifested in those variants of modern art, where the motives of dissolution, destruction predominate, for example, in installations on the "garbage" of civilization. The generic fatigue is also felt in the context of the general human fatigue from information overload and the "curse of the century - haste", which in turn leads to a variety of mental epidemics in society, outbreaks of suicidal moods, to a teenage consciousness in politics turned inside out [10].

Without purporting to exhaustive disclosure of the phenomenon of fatigue, it is worth giving a subtle remark from the talented psychoanalyst Maria Luisa von Franz that the world is driven not by sex, but by laziness. It is exactly the overcoming of laziness that created human civilization, but modern mankind has fallen into an extreme: it seems to have stopped enjoying laziness, it has failed to get rid of fatigue through laziness, having got lost in the standards of the "man" sphere, and having lost the taste for individual laziness. In this case, the indicated existential paradox is not a call back to "oblomovka", it is a question of an "era", a stop in motion called an endless business rush. It was not for nothing that K. Marx defined the society of the future as existing outside labor, and E. Fromm in the twentieth century, interpreting Marx, considered the phenomenon of "just being" as the overcoming of the phenomenon of "having", with its nonsense, labor targeted at consumption. In this relation we can remember bone-idle Figaro from "The Marriage of Figaro" by Beaumarchais, and so he appears to keep the whole intricate plot of the play.
In the article of Olga P. Zubets "Idleness and laziness", which has already been mentioned, the author tries to divide the notions stated in the title, giving credit for "idleness" in the history of human civilization, she insists that idleness is essentially a synonym for aristocratism not only in the worst forms of incarnation (arrogance, isolationism, etc .) but also in possible "heroic" forms — the ancient occupation of philosophy, medieval tournaments, the prospect of an idle prosperity in the societies of the future. Olga P. Zubets writes at the end of her article: "... idleness is a form of heroic. It is not by chance that Marx called the Middle Ages the epoch of heroic laziness, although the latter word deserves a replacement. The value context of aristocratism, which formed in post-traditional morality a hidden area of impracticality - idleness, also brought to it its heroics of historicism". Laziness is estimated by the author of the article exclusively negatively. It is with this position that we beg to disagree.

Laziness as an existential phenomenon, from our point of view, is a more capacious concept than "idleness": using the Euler circles, we would include the concept of "idleness" in the content of the concept of "laziness". No one will deny that the concept of laziness hides a negative meaning, just as no one will dare to deny the positive meaning inherent in the notion of labor, no matter that idleness is said to uplift the human nature. However, it is really possible to be lazy in different ways, and the main danger in our time is the absence of laziness at all. Hegel was right in asserting the eternal dialectical opposition of extremities: the necessity is followed by the accidental, the beauty is followed by the ugliness, doing the work is followed by laziness. If after work there is no rest, if we work without any hope for being idle (that means we have no hope for a holiday), then we are approaching to self-destruction. The Lord, who created this world, did have rest, the commandment to have rest is well known: in Judaism it is Saturday, in Christianity it is Sunday. It is worth noting that all the major revolutions (the Great French revolution, the October revolution in Russia), after which the calendars had to be remade, first of all took on fixed days off, and so their ideologies ceased to exist in the foreseeable historical perspective.

\section{CONCLUSION}

Coming back to the beginning of this study, when the relationship between "self-knowledge" and "self-concern" in the ancient world was considered, we can draw a number of resulting conclusions. First, a human has never renounced from self-concern, the concern has served as a less rational (less rigidly outlined or obviously manifested) self-attitude, and, consequently, as less stiff, ossified, having more diverse possibilities in its implementation. Secondly, it is concernment of a human to achieve not only pleasure (primitive hedonism of Cyrenaics), but the fullness of happiness (eudemonia) that pushed to the search for the impossible, that is aspirations for a better life in the process of life itself (Socratic maieutics, Cynical asceticism). Thirdly, self-concern was essentially the overcoming of natural egocentrism: the dynamism of a person concerned with the search for a dignified life did not allow him to focus only on 
reaching momentary benefits, leading to spiritual aristocracy, "high idleness". Apparently, it is no coincidence that the ancient world eventually made philosophy a "school" discipline, recognizing for the eccentric philosophers the right to be included in the basic education. Fourthly, the modern society, no matter if it is driven by the Western or Oriental culture, is immersed in such a rhythm of existence in which the place of "high idleness" engendered by the "self-concern" of an authentic person, is occupied mainly by the "care of yourself" as "of someone else", this care depersonalizing the person. Martin Heidegger brilliantly revealed this in his works.

The XXI century has made only few changes in the solution of the problem of authenticity. On the contrary, it finally deprived the person of that nice attributes of the past, which at least at the physical level brought back the uniqueness to the person: instead of writing on paper the "push-button culture" of sending information (over telephone, the Internet, etc.) has appeared; instead of face-to-face communication there is a text-to-text conversation; instead of national clothes people wear same-type uniform clothes; instead of reading we have video sequences; instead of tropical jungle there is concrete jungle and many more "instead ..." [11].

What if one raises the question of whether there is a chance for mankind to get out of this falling into nothingness, climb out of existing not just beyond the real, but in general beyond the being, in which the haste "ate", ground not only our authenticity but the very being, turning us into copies of ourselves? The answer, as we see it, will still be positive: if the "trans-man" is possible in the evolutionary plan, then it will be like the acquisition of the "well-overlooked old", a return to the sources of self-realization but not the absolutely new being of a constructed technicalized monster. A human is certainly given the opportunity to interact dynamically with eternity: with eternal values, with eternal aspiration to unattainable happiness, eternal search for truth, eternal expectation of love and eternal search for perfection even through the realization of the impossible [12].

Ancient culture again makes modern people "try on" its values: for us it has lost all the intricacies of political regimes but it also opens our eyes to the amazing opportunities for people to find "high idleness" in "self-concern".

\section{REFERENCES}

[1] Ivanchenko G.V. Self-concern: history and modernity. Moscow, Smysl, 2009.

[2] Lebedev S.A. The Structure of Scientific Rationality // Voprosy filosofii. 2017. № 5. P. 66-79.

[3] Zemtsov B.N. Right as World Outlook Value of the Power (XX Century) // Tomsk State University Journal of History. 2014. No. 4 (30). P. 28-34.

[4] Dodds E. R. The Greeks And The Irrational. St. Petersburg: Aleteya, 2000 .

[5] Plato. Dialogues. EKSMO, 2015.

[6] Nekhamkin V.A. A counterfactual Challenge of the Past: Ways of Negotiation // Herald of the Russian Academy of Sciences. 2017. Vol 87. Issue 2. P. 191-198. DOI: 10.1134/S1019331617020046.
[7] Zubets O.P. Idleness and laziness / / Ethical thought. Ed.3 / resp. ed. A. A. Huseynov M.: IF RAS, 2002. P. 118-137.

[8] Anthology of Cynicism. Moscow, Nauka, 1984.

[9] Gubanov N.I., Gubanov N.N. The role of mentality in the development of society: sociocultural hypothesis // Vestnik slavianskikh kultur-bulletin of slavic cultures-scientific and informational journal. 2017. Vol. 43. № 1. P. 38-51.

[10] Suzdaleva T.R. Migratory processes in the context of geopolitics // Vestnik Tomskogo gosudarstvennogo universiteta-Filosofiyasotsiologiya-politologiya-Tomsk state university journal of philosophy sociology and political science. 2016. № 3 (36). P. 237 244. DOI: $10.17223 / 1998863 \mathrm{X} / 35 / 25$

[11] Oseledchik M.B., Ivlev V.Yu., Ivleva M.L. Using social networks in knowledge management system //Proceedings of the 2nd International Conference on Culture, Education and Economic Development of Modern Society (ICCESE 2018). Moscow, Russia. Pp.911-914.

[12] I.P. Kavinova Philosophical, religious and social aspects of transhumanism, or overcoming the "human, too human" in the XXI century / / Humanities Bulletin of BMSTU. 2017, No. 3 (53), P.3. 